\title{
Nonmonotonic Effects of Chronic Low-Dose Di(2-ethylhexyl) Phthalate on Gonadal Weight and Reproductive
}

\author{
Sunyeong Cha ${ }^{1}$, Kayeon Jung ${ }^{1}$, Min Young Lee ${ }^{1}$, Yeon Jeong Hwang ${ }^{1}$, Eunhyeok Yang ${ }^{1}$, \\ Sung-Ho Lee ${ }^{2}$, Hyo-il Jung ${ }^{3}$, and ${ }^{\dagger}$ Yong-Pil Cheon ${ }^{1}$ \\ ${ }^{I}$ Division of Developmental Biology and Physiology, School of Biological Sciences and Chemistry, \\ Sungshin University, Seoul 02844, Korea \\ ${ }^{2}$ Dept. of Lifesicence, Sangmyung University, Soeul 03016, Korea \\ ${ }^{3}$ School of Mechanical Engineering, Yonsei University, Seoul 03722, Korea
}

\begin{abstract}
Endocrine disruptors have been concerned in toxicology but now challenged as physiological point especially concerned with exposing dose and period. In this study the low-dose chronic administration of di(2-ethylhexyl) phthaltae (DEHP) during reproductive period was examined to evaluate the possible roles. Adult male and female CD-1 mice were exposed to DEHP with drinking water containing $133 \mu \mathrm{g} / \mathrm{L}$ and 1,330 $\mu \mathrm{g} / \mathrm{L}$ DEHP in water according to OECD 433 guide line and sacrificed just after weaning. The weights of uterus and ovary were decreased by drinking of 1,330 $\mu \mathrm{g} / \mathrm{L}$ DEHP water. There was not adverse effects on either accumulated mating rate and mating rate depend on estrus stage, pregnancy duration, and sex ration at birth. However, the accumulated rate of successful delivery and litter size were significantly high at 1,330 $\mu \mathrm{g} / \mathrm{L}$ DEHP water. The number of epididymal sperm was significantly increased by drinking of $1,330 \mu \mathrm{g} / \mathrm{L}$ DEHP water. In addition, the number of follicles (primary, secondary, tertiary) were more many than control at 1,330 $\mu \mathrm{g} / \mathrm{L}$ DEHP water drunk mother. Though further studies are needed to identify what are the mechanism of DEHP in folliculogenesis and spermatogenesis. From this study we firstly report the effect of low-dose chronic administration of DEHP with drinking could change the ovarian follicle population size and spermatogenesis rate. Put together, those finding is different from previous high-dose effects and suggest the physiological role of DEHP in gonads and uterus.
\end{abstract}

Key words : Low-dose DEHP, Folliculogenesis, Spermatogenesis, Reproductive period

\section{INTRODUCTION}

Dialkyl phthalates are widely used in plastics, hugely synthesized chemicals, and exposed ubiquitously to human. Until early 2000s more than 18 billion pounds of phthalates are used every years (Bizzari et al., 2000; Blount et al., 2000; Guo et al., 2011). Di(2-ethylhexyl) phthalate
(DEHP, CAS NO: 117-81-7) is one of the most popular phthalates: it has been used from 1930s and the production volume is about 2 million tons in 1999 (Center for the Evaluation of Risks to Human Reproduction, 2000). In general population, the urinary phthalate metabolites are detectable (Silva et al., 2004). Because DEHP is a suspected endocrine disrupting chemicals (EDC) in human, its amount are

\footnotetext{
Manuscript received February 7, 2018, Received in revised form March 22, 2018, Accepted March 26, 2018

† Corresponding Author : Yong-Pil Choen, Division of Developmental Biology and Physiology, Department of Biotechnology, Sungshin Women's University, Seoul 02844, Korea. Tel: +82- 2-920-7639, Fax: +82-2-920-2736, E-mail: ypcheon@ sungshin.ac.kr
}

This is an Open Access article distributed under the terms of the Creative Commons Attribution Non-Commercial License (http:// creative-commons.org/licenses/by-nc/3.0) which permits unrestricted non-commercial use, distribution, and reproduction in any medium, provided the original work is properly cited. 
regulated for manufacture the industrial products in almost countries (for example, $800 \mathrm{mg} / \mathrm{kg}$ in REACH SVHC, 0.1 $\mathrm{wt} \%$ in USA, $1,000 \mathrm{mg} / \mathrm{kg}$ in Hongkong). However, it is still used to make for many commercial products including sprays, toy, raincoats, lubricants, cosmetics, and medical devices such as blood bags and dialysis equipment (Liu et al., 2017).

Phthalates show toxicity in human and wild animals (Kavlok et al., 2002). It is known that the toxicity of phthalate is dependent on the chemical structures and administered dosage, and administered life stage (Parks et al., 2000; Foster 2006). DEHP has the most potent toxicity in reproduction among phthaltes (Heindel et al., 1989; Davis et al., 1994). In human, female factory workers exposed chronically to high levels of phthalates is associated with decreased rates of pregnancy (Aldyreva et al., 1975). Interestingly, in vivo, $2 \mathrm{~g} / \mathrm{kg}$ DEHP causes anovulation in adult cycling rats (Lovekamp-Swan \& Davis, 2003). Numerous studies were performed with phthalate and revealed the anti-androgenic effects in male rat at medium and from 10 $\mathrm{mg} / \mathrm{kg} /$ day levels in depend on the age (Jarfelt et al., 2005; Christiansen et al., 2010). However so for confused and controversy about the effects of such exposure. An epidemiological study in US EPA could not find the relationship between reproductive toxicity and phthalate (ACEIII, 2013). Someone suggested that in these epidemiological studies the range of dose is much lower than previous toxicological studies (Lovekamp-Swan and Davis, 2003; Jarfelt et al., 2005; Andrade et al., 2006), but others ask new viewpoints (Rhomberg \& Goodman, 2012; Vandenberg et al., 2012; Zoeller et al., 2012).

Previously, the Agency for Toxic Substances and Disease Registry (ATSDR) estimates that the maximum daily exposure to DEHP for the general population is about 2 $\mathrm{mg} /$ day. So the low dose of phthalate is permitted. Controversy for the review of ACEIII (2013), a few studies showed toxicity of low dose phthalate in male infertility and steroidogenesis (Bloom et al., 2015; Savchuk et al., 2015).
Recently it become a big issue to study the effect of very low dosage EDC with long period (Kawaguchi et al., 2015; $\mathrm{Xu}$ et al., 2017). In addition, so far, it is largely masked the effects of DEHP during reproductive period. Therefore in this study, the effects of very low dose DEHP on the body weight, reproductive organ weight and reproduction were evaluated in reproductive period female mice and male employed the OECD test guideline 443 "the expended one-generation reproductive toxicity study" for parents.

\section{MATERIALS AND METHODS}

\section{Experimental animals}

CD-1 mice (10-12 weeks old) were used for parental group. All experimental animals were studied according to the Guide for the Care and Use of Laboratory Animals published by the National Institutes of Health under the Experimental Animals Committee of Sungshin Women's University. They were maintained under controlled temperature $\left(22-24^{\circ} \mathrm{C}\right)$, humidity $(45-55 \%)$ and light $(14 \mathrm{~h}$ light/10 h dark) conditions and were fed phytoestrogen free diet (2018 Teklad global 18\% protein rodent diet; ENVIGO, Madison, WI, USA). and water (free or DEHP containing) ad libitum using glass bottles. Pregnant mice were allowed to deliver their pups naturally and were weaned at 21 post-natal days.

\section{Chemical treatments}

Di(2-ethylhexyl)phthalate (DEHP Sigma Aldrich Cat\# 36735) was selected as a endocrine disrupting chemicals and used at two concentration based on Niermann et al. (2015): $133 \mu \mathrm{g} / \mathrm{L}$ and $1,330 \mu \mathrm{g} / \mathrm{L}$ in drinking water. 10 female and 10 male mice were involved in each groups. The chemical stock solution was prepared in purified water and stored at $-20^{\circ} \mathrm{C}$. Administration was proceeded to parents according on schedule suggested by OECD test guideline 443. Briefly, animals were administered in drinking water containing DEHP during 10 weeks (pre-mating; 
2 weeks, mating; 2 weeks, post mating included pregnancy and lactation; 6 weeks) and then were anatomized for organ sampling.

\section{Body and organ weight}

The control and experimental groups of the same sex were sacrificed at the same time. The males and females mice were sacrificed at end of chemical treatment periods for 10 weeks, and the reproductive organ (testes and epididymis in males; ovary and uterus in females) were excised out and weighed individually. Relative organs weight was calculated based on organ to body weight.

\section{Sperm count}

The number of sperm was counted with Makler counter chamber (Sefi Medical Instruments LTD, Santa Ana, CA, USA). The caudal sperm collection was followed the method for mouse in vitro fertilization (Hogan et al., 1994).

\section{Histology and count the number of follicles}

Extracted ovaries were weighted with electronic balance and fixed with $4 \%$ paraformaldehyde in PBS. And then the paraffin embedded ovaries were sectioned for histological studies (4 $\mu \mathrm{m}$ thickness). Sections were stained with $\mathrm{He}-$ matoxylin and Eosin. The $13^{\text {th }}$ section of serial section from the surface were used for follicle count. Follicle stage was defined as primordial, primary, secondary, and tertiary follicle (Rybska et al., 2018).

\section{Statistical analysis}

The results represent means $\pm \mathrm{SED}$. The data were analyzed using one-way analysis of variance (ANOVA) and $t$ test between control and experimental group. In all cases, values of $p<0.05$ were deemed to indicate statistical significance.

\section{RESULTS}

\section{Reproductive organ weight}

Within the examined dosage range, the weight of testis or epididymis were not different from them of the control (Table 1). In female mice, the ovarian weight significantly decreased in DEHP 1,330 $\mu \mathrm{g} / \mathrm{L}$ drinking group (Table 1). The uterine weight also decreased in DEHP $1,330 \mu \mathrm{g} / \mathrm{L}$ drinking group (Table 1).

\section{Effects of DEHP on reproductive outcome}

The mice which were pre-administered with DEHP for 2 weeks before attended reproduction, were housed for 2 weeks to know the effects of DEHP on the reproduction. The accumulated mating rates were not different between groups (Fig. 1A) and the mating rates at estrus stage were not changed by DEHP administration (Fig. 1B).

The pregnancy duration was from $20.10 \pm 0.216$ to $20.35 \pm 0.109$ and not statistically different between groups (Fig. 2A). On the other hand, the successful delivery rate was significantly high at DEHP $1,330 \mu \mathrm{g} / \mathrm{L}$ drinking group

Table 1. Relative weight (mg) of reproductive organs to body weight in di(2-ethylhexyl) phthalate (DEHP) drunk mice

\begin{tabular}{ccccccccc}
\hline \multirow{2}{*}{ Group } & \multicolumn{2}{c}{ Ovary } & \multirow{2}{*}{ Uterus } & \multicolumn{2}{c}{ Testis } & & \multicolumn{2}{c}{ Epididymis } \\
\cline { 2 - 3 } & Left & Right & & Left & Right & & Left & Right \\
\hline Control & $25.0 \pm 7.0$ & $25.1 \pm 2.4$ & $260.1 \pm 28.3$ & $143.6 \pm 15.1$ & $145.1 \pm 8.3$ & & $56.6 \pm 4.3$ & $57.8 \pm 5.5$ \\
DEHP 133 & $33.5 \pm 9.0$ & $20.0 \pm 4.0$ & $288.8 \pm 41.6$ & $152.0 \pm 5.4$ & $142.0 \pm 4.6$ & & $60.1 \pm 4.6$ & $60.5 \pm 4.5$ \\
DEHP 1330 & $15.2 \pm 2.8^{*}$ & $15.7 \pm 2.5$ & $174.7 \pm 12.1^{*}$ & $149.3 \pm 8.8$ & $136.2 \pm 6.2$ & & $66.6 \pm 13.8$ & $62.0 \pm 5.1$ \\
\hline
\end{tabular}

${ }^{*} p<0.05$ ( $t$-test, control vs DEHP). 
A

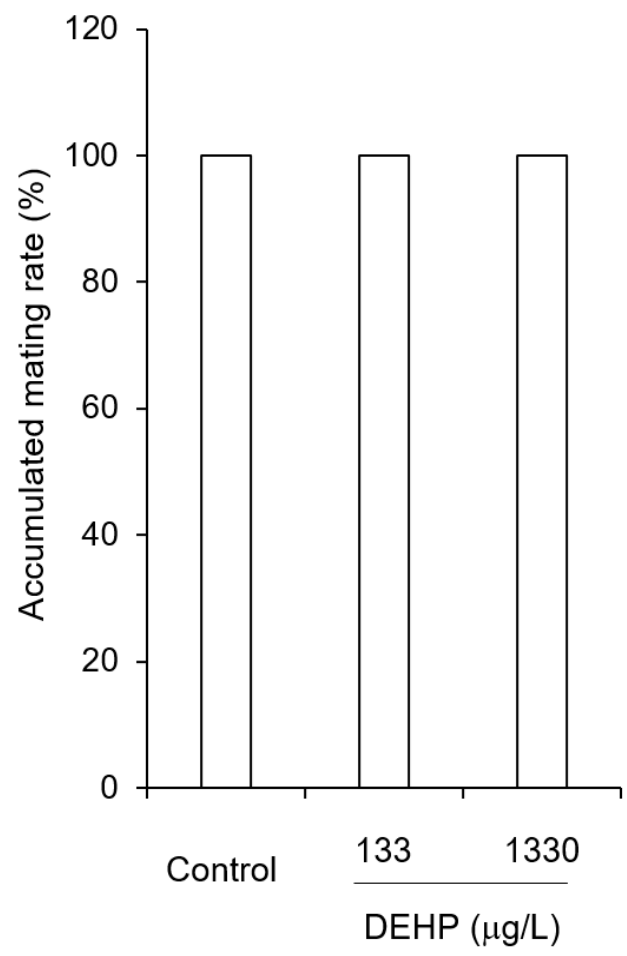

B

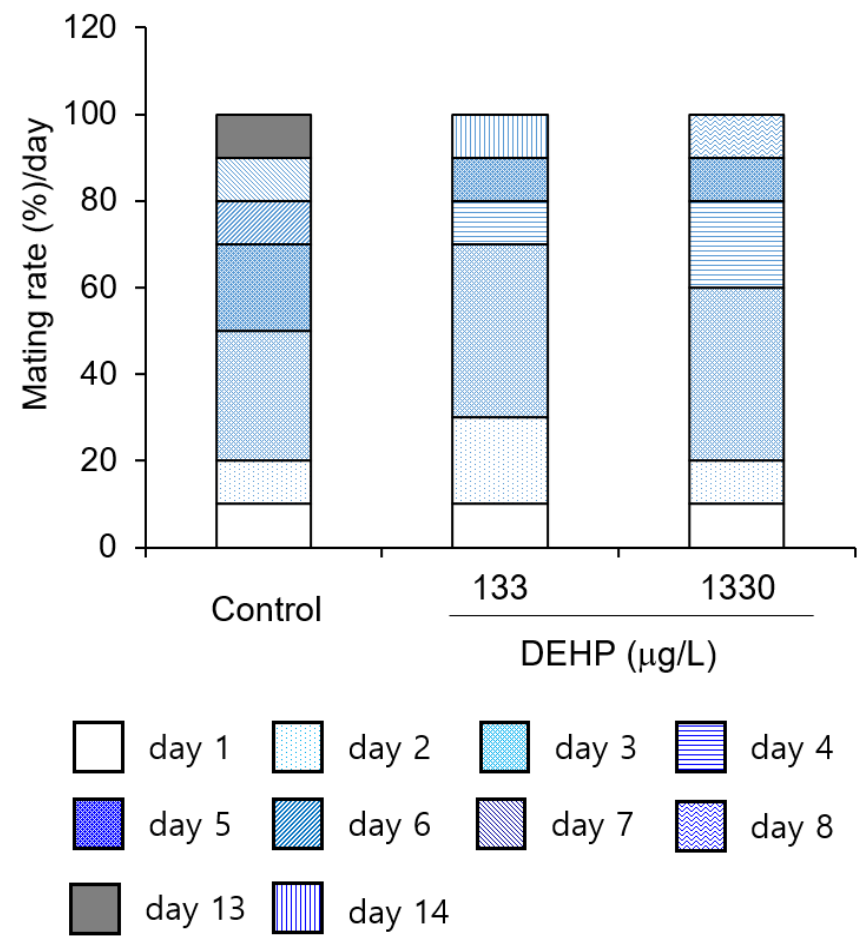

Fig. 1. The effects of DEHP on accumulated mating rate (A) and estrus cycle dependent mating rates (B). DEHP was administered with drink according to the phytoestrogen free generation F0 according to the OECD Test Guide line 443. Accumulated mating rates and the estrus cycle dependent mating rates were not affected by DEHP administration.

compared with others (Fig. 2B). However, the sex ratios of pubs were not different between groups. The percentages of male among pubs were $48.46 \pm 4.328$ at control, $46.29 \pm$ 4.397 at DEHP $133 \mu \mathrm{g} / \mathrm{L}$, and 48.74 $\pm 2.624 \mu \mathrm{g} / \mathrm{L}$ (Fig. 3).

The litter sizes were different between groups. As seen at Table 2, it was dramatically increased in DEHP 1,330 $\mu \mathrm{g} / \mathrm{L}$ drinking group $(p<1 \mathrm{E}-8)$.

\section{Effect of DEHP on the sperm count and follicle} number

To evaluate the possible role of DEHP on the litter size, the number of caudal epididymal sperm and the follicles in ovary was counted. The numbers of sperm were increased concentration-dependently by administration of DEHP. The ratio of sperm count to body weight in caudal epididymis was $0.39 \pm 0.051,0.46 \pm 0.050$, and $0.54 \pm 0.073$, re- spectively at control, DEHP $133 \mu \mathrm{g} / \mathrm{L}$, and DEHP 1,330 $\mu \mathrm{g} / \mathrm{L}$ (Fig. 4).

The large number of follicles were detected at DEHP $1,330 \mu \mathrm{g} / \mathrm{L}$ drunk mother group. The numbers of primary, secondary, and tertiary follicles were significantly many more compared to control and DEHP $133 \mu \mathrm{g} / \mathrm{L}$ drunk mother groups (Fig. 5A). It is hard to find the primordial follicles in germinal epithelia of control sections (Fig. 5B).

\section{DISCUSSION}

Previously we reported that very low-dose chronic administration of nonylphenol can work as endocrine disruption (Cha et al., 2017) and other groups also suggest the possible role of low-dose EDC chemicals in physiological levels. For example, exposing very low DEHP from gesta- 
A

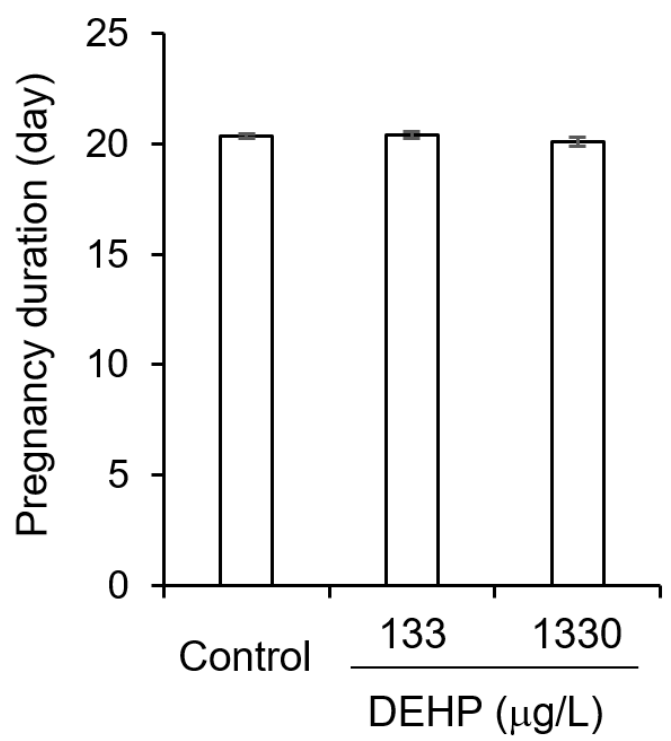

$\mathrm{B}$

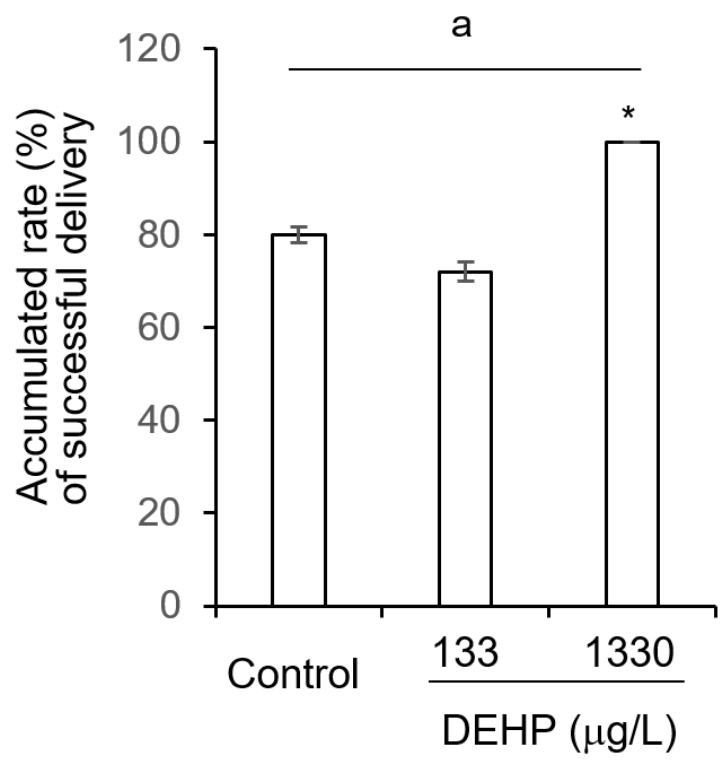

Fig. 2. The effect of DEHP on pregnancy duration (A) and successful delivery rate (B). DEHP was administered with drink for 10 weeks (from pre-mating to lactation). Copulation plugs were checked every day morning. To keep the strict time for mating, the female which did not have copulation plug, were separated at morning and caging again with mael at 5:00 pm. There was no difference in gestational periods. However the delivary rate was decreasedd in control and $133 \mu \mathrm{g} / \mathrm{L}$ DEHP compared with $1,330 \mu \mathrm{g} / \mathrm{L}$ DEHP. a: $p<0.05$ (One wasy ANOVA). *: $p<0.05$ ( $t$-test, control vs DEHPs).

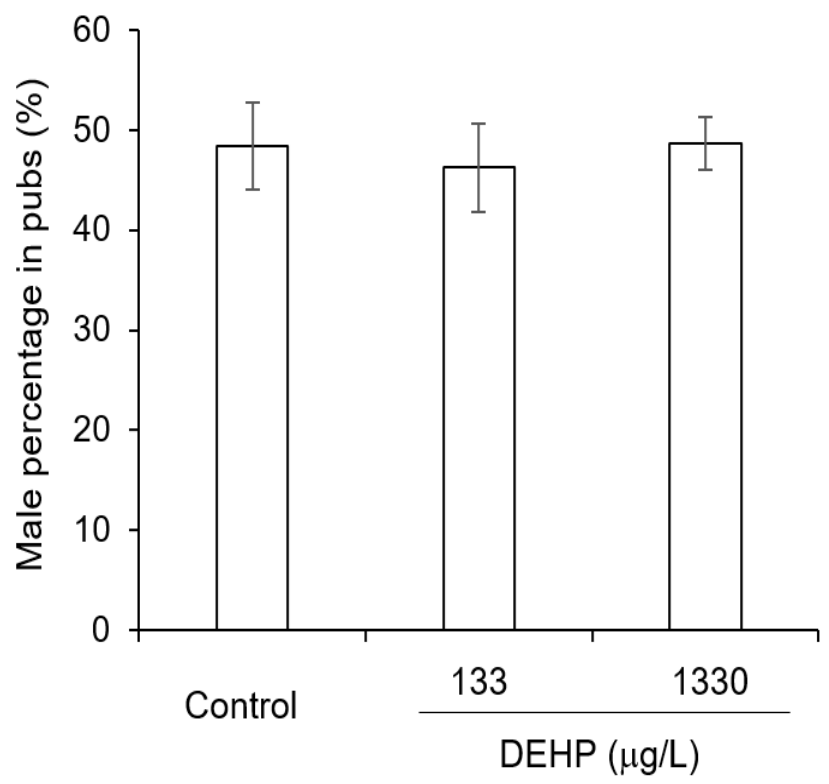

Fig. 3. The sex ratios in pubs. The parents were fed with DEHP containing water for 10 week and attended reproduction. The sex of offspring were identified at day 1 of birth. DEHP did not effect on sex ratios.
Table 2. Effect of di(2-ethylhexyl) phthalate (DEHP) on litter size of parents which were exposed for reproductive period

\begin{tabular}{cccc}
\hline \hline Generation & Group & No. female & Litter size \\
\hline \multirow{4}{*}{$\mathrm{P}_{0}$} & Control & 10 & $9.0 \pm 0.71$ \\
& DEHP 133 & 10 & $8.0 \pm 1.48$ \\
& DEHP 1330 & 10 & $11.6 \pm 0.88^{*}$ \\
\hline${ }^{*} p<0.05$ (t-test, control vs DEHP).
\end{tabular}

tion day 11 to birth increases preantral follicle numbers and caused of some breeding abnormalities (Niermann et al., 2015). Four weeks drinking of 50 and $500 \mu \mathrm{g} / \mathrm{L}$ NP has multigenerational effect on selective reproductive organ (Kyselova et al., 2003). Therefore, now the studies at the level of physiology become more important (Vandenberg et al., 2012; Zoeller et al., 2012). 


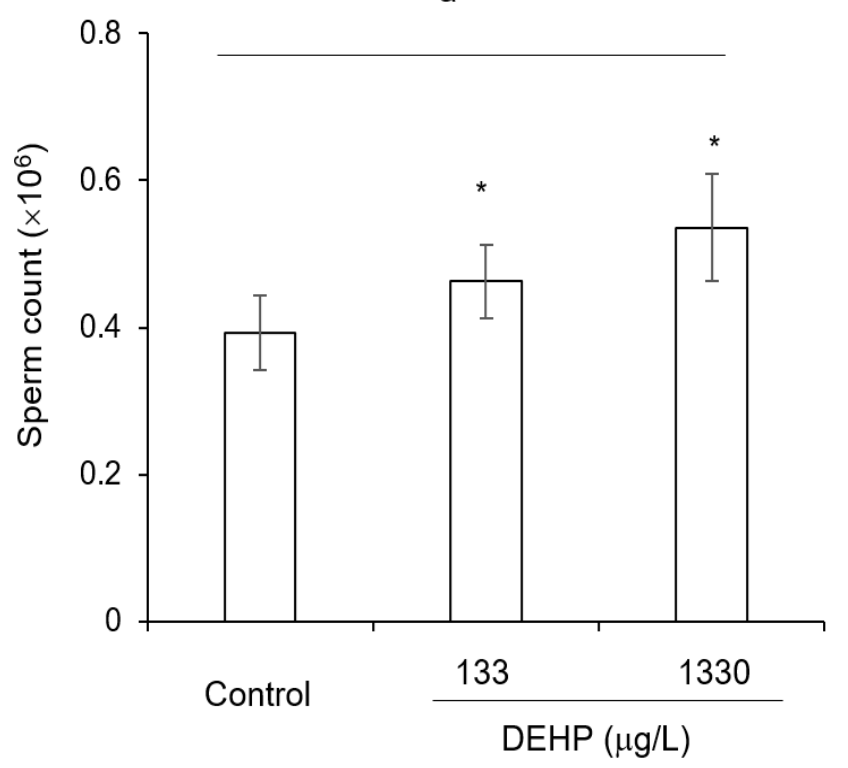

Fig. 4. The ratio of sperm count to body weight in caudal epididymis. The caudal epididymis was isolated and extracted the sperms by squeeze and mincing. The number of sperms were counted with Makler chamber. a: $p<0.05$ (One way ANOVA). *: $p<0.05$ ( $t$-test, control vs DEHPs).

A

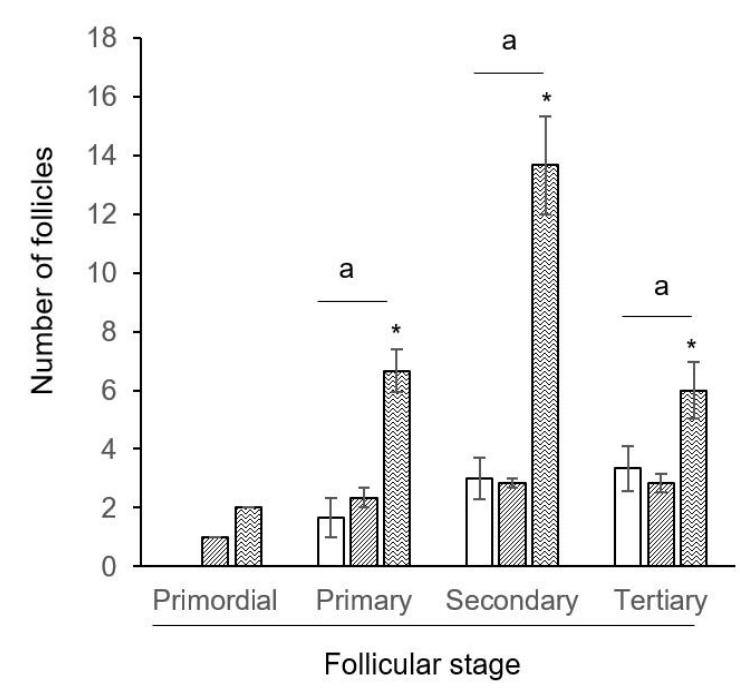

B

Many studies have been in relatively high dosage (Lovekamp-Swan \& Davis, 2003; Christiansen et al., 2010). Reproductive and developmental toxicity studies did in the female rodent during organogenesis (Kaul et al., 1982). In mouse toxicity is dose-dependent and timing of exposure (Tomita et al., 1986). DEHP administration in adult rats induce hypoestrogenic anovulatory cycles and polycystic ovaries (Davis et al., 1994; Lovekamp-Swan \& Davis, 2003). DEHP induce atresia of tertiary follicles (Grande et al., 2007) and cause of endometriosis and uterine leiomyoma (Weuve et al., 2010). However, interestingly, the lowdose chronic administration of DEHP had opposite results from the previous reports conducted with high dosage.

In this study, the litter size was significantly big and the accumulated rate of successful delivery was increased dramatically at $1,330 \mu \mathrm{g} / \mathrm{L}$ DEHP drunk mother compared with control. On the other hand the weights of ovary and uterus were decreased at this condition. These results is inconsistent to the known general role of EDC. Such a

B

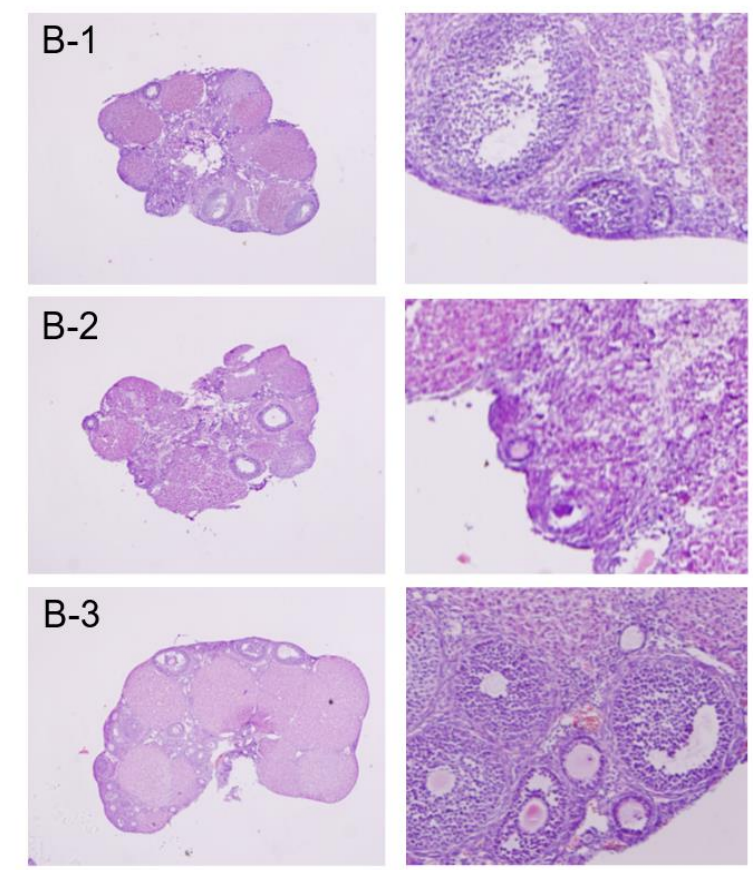

Fig. 5. The number of follicles (A) and photomicrograph of the ovary (B) in DEHP water drunk mice. The number of each stage follicles were counted in $13^{\text {th }}$ section of serial section from the surface. Those were counted from 6 sections in each treatment groups. a: $p<0.05$ (One wasy ANOVA). *: $p<0.05$ ( $t$-test, control vs DEHPs). 
phenomena also reported other groups with another ECDs (Vandenberg et al., 2012).

The weight of ovary and uterus were decreased by administration of DEHP. In this study, the reasons of such results is not clear and needed further studies. In a dosedependent manner MEHP decreases granulosa cell aromatase expression (Lovekamp-Swan \& Davis, 2003). In human based studies, the phthaltate metabolites are revealed the main cause of reproductive abnormality as phthalate. Infertility risks are increased in MEHP dose-dependent manner in Chinese men (Liu et al., 2017). It has been suggested that such results from the antagonist effects of MEHP in vitro (Stroheker et al., 2005). However, it is needed further study how its effects are arise from what DEHP metabolite after absorption into the body. Because these metabolite has been suggested as a real reason of the DEHP toxicty (Gray \& Beamand, 1984).

Interestingly primary, secondary, and tertiary follicles were significantly many more at DEHP $1,330 \mu \mathrm{g} / \mathrm{L}$ drinking groups than the control. On the other hand, the sperm count also increased in DEHP drinking male groups compare to control. These interesting phenomena are first time discovery. The study of Niermann et al (2015) also showed the increase the preantral follicle number of low DEHP (exposed from gestation day 11 to birth) but the exposing period is different from this study. The suggested mechanisms which affects reproductive function are various including follows: an anti-androgenicity (Latini et al., 2003; Akingbemi et al., 2004), suppressor of the expression of steroidogenesis related factors and activation of PPARs (Borch et al., 2006; Howdeshell et al., 2007; Wilson et al., 2008), activator of caspanse-3 in specific cells through deacetylation of SP3 (Guida et al., 2014), and inducing agent of inflammation (Ferguson et al., 2012). Recently a suggested mechanisms of phthalate is the role of low dose of phthalate as androgen effects on steroidogenesis but high doses as antiandrogen action (Fan et al., 2010; Li et al., 2016; Liu et al., 2017).
From this study we firstly report the effect of low-dose chronic administration of DEHP with drinking could change the ovarian follicle population. Though further studies are needed to identify what are the mechanism of DEHP in folliculogenesis. In addition, it is also needed the studies why the number of sperm is increased DEHP. Put together, those finding is different from previous high-dose effects and suggest the physiological role of DEHP in gonads.

\section{ACKNOWLEDGEMENT}

We thank to Chaelim Kim for assistance. This study was supported by a grant of National Research Foundation of Korea (NRF-2015M3A9D7067365).

\section{REFERENCES}

ACEIII (2013) America's Children and the Environment Third Edition. https:/www.epa.gov/sites/production/files/ 2015-06/documents/ace3_2013.pdf.

Akingbemi BT, Ge R, Klinefelter GR, Zirkin BR, Hardy MP (2004) Phthalate-induced Leydig cell hyperplasia is associated with multiple endocrine disturbances. Proc Natl Acad Sci USA 101:775-780.

Aldyreva MV, Klimova TS, Iziumova AS, Timofeevskaia LA (1975) The effect of phthalate plasticizers on the generative function. Gig Tr Prof Zabol 19:25-29.

Andrade AJM, Grande SW, Talsness CE, Gericke C, Grote K, Golombiewski A, Sterner-Kock A, Chahoud I (2006) A dose response study following in utero and lactational exposure to di-(2-ethylhexyl) phthalate (DEHP): Reproductive effects on adult male offspring rats. Toxicology 228:85-97.

Bizzari S, Openbert B, Iskikava Y (2000) Plasticizers. Chemical Economics Handbook. Palo Alto, CA, SRI International.

Bloom MS, Whitcomb BW, Chen Z, Ye A, Kannan K, Louis GB (2015) Associations between urinary phthalate 
concentrations and semen quality parameters in a general population. Hum Reprod 30:2645-2657.

Blount BC, Milgram KE, Silva MJ, Malek NA, Reidy JA, Needham LL, Brock JW (2000) Quantitative detection of eight phthalate metabolites in human urine using HPLC-APCI-MS/MS. Anal Chem 72:4127-4137.

Borch J, Metzdorff SB, Vinggaard AM, Brokken L, Dalgaard M (2006) Mechanisms underlying the antiandrogenic effect of diethylhexyl phthalate in fetal testis. Toxicology 223:144-155.

Center for Devices and Radiological Health, US Food and Drug Administration (2001) http://www.fda.gov/cdrh/ ost/dehp-pvc.pdf.

Cha S, Baek JW, Ji HJ, Choi JH, Kim C, Lee MY, Hwang YJ, Yang E, Lee SH, Jung H, Cheon YP (2017) Disturbing effects of chronic low-dose 4-nonylphenol exposing on gonadal weight and reproductive outcome over one-generation. Dev Reprod 21:121-130.

Christiansen S, Boberg J, Axelstad M, Dalgaard M, Vinggaard AM, Metzdorff SB, Hass U (2010) Low-dose perinatal exposure to di(2-ethylhexyl) phthalate induces anti-androgenic effects in male rats. Reprod Toxicol 30:313-321.

Davis BJ, Maronpot RR, Heindel JJ (1994) Di-(2-ethylhexyl) phthalate suppresses estradiol and ovulation in cycling rats. Toxicol Appl Pharmacol 128:216-223.

Fan J, Traore K, Li W, Amri H, Huang H, Wu C, Chen H, Zirkin B. 2010. Molecular mechanisms mediating the effect of mono-(2-ethylhexyl) phthalate on hormonestimulated steroidogenesis in MA-10 mouse tumor Leydig cells. Endocrinology 151:3348-3362.

Ferguson KK, Loch-Caruso R, Meeker JD (2012) Exploration of oxidative stress and inflammatory markers in relation to urinary phthalate metabolites: NHANES 1999-2006. Environ Sci Technol 46:477-485.

Foster PM (2006) Disruption of reproductive development in male rat offspring following in utero exposure to phthalate esters. Int J Androl 29:140-147.
Grande SW, Andrade AJM, Talsness CE, Grote K, Golombiewski A, Stemer-Kock A, Chahoud I (2007) A dose-response study following in utero and lactational exposure to di-(2-ethylhexyl) phthalate (DEHP): Reproductive effects on adult female offspring rats. Toxicology 229:114-122.

Gray TJB, Beamand JA (1984) Effect of some phthalate esters and other testicular toxins on primary cultrues of testicular cells. Food Chem Toxicol 22:123-131.

Guida N, Laudati G, Galgani M, Santopaolo M, Montuori P, Triassi M, Renzo GI, Canzoniero Mt, Formisano L (2014) Hiiistone deacetylase 4 promotes ubiquitindependent porteasomal degradation of Sp3 in SH-SY5Y cells treated with di(2-ethylhexyl) phthalate (DEHP), determining neuronal death. Toxicol Appl Pharmacol 280:190-198.

Guo Y, Wu Q, Kannan K (2011) Phthalate metabolites in urine from China, and implications for human exposures. Environ Int 37:893-898.

Heindel JJ, Gulati DK, Mounce RC, Russell SR, Lamb JC IV (1989) Reproductive toxicity of three phthalic acid esters in a continuous breeding protocol. Toxicol Sci 12:508-518.

Howdeshell KL, Furr J, Lambright CR, Rider CV, Wilson VS, Gray LE Jr (2007) Cumulative effects of dibutyl phthalate and diethylhexyl phthalate on male rat reproductive tract development: Altered fetal steroid hormones and genes. Toxicol Sci 99:190-202.

Jarfelt K, Dalgaard M, Hass U, Borch J, Jacobsen H, Ladefoged $O$ (2005) Antiandrogenic effects in male rats perinatally exposed to a mixture of di(2-ethylhexyl) phthalate and di(2-ethylhexyl) adipate. Reprod Toxicol 19:505-515.

Kaul AF, Souney PF, Osathanondh R (1982) A review of possible toxicity of di-2-ethylhexylphthalate (DEHP) in plastic intravenous containers: Effects on reproduction. Drug Intell Clin Pharm 16:689-692.

Kavlok R, Boekelheide K, Chapin R, Cunningham M, 
Faustman E, Foster P, Golub M, Henderson R, Hinberg I, Little R, seed J, Shea K, Tabacova S, Tyl R, Williams P, Zacharewski T (2002) NTP center for the evaluation of risks to human reproduction: phthalates expert panal reprot on the reproductive and developmental toicity of di(20dthylhexyl) phthatlate. Reprod Toxicol 16:529653.

Kawaguchi S, Kuwahara R, Kohara Y, Uchida Y, Oku Y, Yamashita K (2015) Oral exposure to low-dose of nonylphenol impairs memory performance in SpragueDawley rats. J Toxicol Sci 40:43-53.

Kyselova V, Peknicova J, Buckiova D, Boubelik M (2003) Effects of p-nonylphenol and resveratrol on body and organ weight and in vitro fertility of outbred CD-1 mice. Reprod Biol Endocrinol 1:30-39.

Latini G, De Felice C, Presta G, Del Vecchio A, Paris I, Ruggieri F, Mazzeo P (2003) In utero exposure to di(2-ethylhexyl) phthalate and duration of human pregnancy. Environ Health Perspect 111:1783-1785.

Li Y, Hu Y, Dong C, Lu H, Zhang C, Hu Q, Li S, Qin H, Li Z, Wang Y (2016) Vimentin-mediated steroidogenesis induced by phthalate esters: Involvement of DNA demethylation and nuclear factor $\mathrm{kB}$. PLoS One 11, e0146138.

Liu L, Wang H, Tian M, Zhang J, Panuwet P, D’Souza PE, Barr DB, Huang Q, Xia Y, Shen H (2017) Phthalate metabolites related to infertile biomarkers and infertility in Chinese men. Environ Pollut 231:291-300.

Lovekamp-Swan T, Davis BJ (2003) Mechanisms of phthalate ester toxicity in the female reproductive system. Environ Health Perspect 111:139-145.

Niermann S, Rattan S, Brehm E, Flaws JA (2015) Prenatal exposure to di-(2-ethylhexyl) phthalate (DEHP) affects reproductive outcomes in female mice. Reprod Toxicol 53:23-32.

Parks LG, Ostby JS, Lambright CR, Abbott BD, Klinefelter GR, Barlow JN, Gray LE Jr (2000) The plasticizer diethylhexyl phthalate induces malformations by decreasing fetal testosterone synthesis during sexual differentiation in the male rat. Toxicol Sci 58:339-349.

Rhomberg LR, Goodman JE (2012) Low-dose effects and nonmonotonic dose-responses of endocrine disrupting chemicals: Has the case been made? Reg Toxicol Pharmacol 64:130-133.

Rybska M, Knap S, jankowski M, jeseta M, Bukowska D, Antosik P, Nowicki M, Zabel M, Kempisty B, Jaskowski JM (2018) Characteristic of factors influencing the proper course of folliclulogenesis in mammals. Med J Cell Biol 6:33-38.

Savchuk I, Söder O, Svechnikov K (2015) Mono-2-ethylhexyl phthalate stimulates androgen production but suppresses mitochondrial function in mouse Leydig cells with different steroidogenic potential. Toxicol Sci 145:149-156.

Silva MJ, Barr DB, Reidy JA, Malek NA, Hodge CC, Caudill SP, Brock JW, Needham LL, Calafat AM (2004) Urinary levels of seven phthalate metabolites in the US population from the National Health and Nutrition Examination Survey (NHANES) 1999-2000. Environ Health Perspect 112:331-338.

Stroheker T, Cabaton N, Nourdin G, Regnier JF, Lhuguenot JC, Chagnon MC (2005) Evaluation of antiandrogenic activity of di-(2-ethylhexyl)phthalate. Toxicology 208:115-121.

Tomita I, Nakamura Y, Yagi Y, Tukikawa K (1986) Fetotoxic effects of mono-2-ethylhexyl phthalate (MEHP) in mice. Environ Health Perspect 65:249-254.

Vandenberg LN, Colborn TC, Hayes TB, Heindel JJ, Jacobs DR, Lee DH, Shioda T, Soto AM, vom Saal FS, Welshons WV, Zoeller RT, Myers JP (2012) Hormones and endocrine-disrupting chemicals: Low-dose effects and nonmonotonic dose responses. Endocrine Reviews $33: 378-455$.

Weuve J, Hauser R, Calafat AM, Missmer A, Wise LA (2010) Association of exposure to phthalates with endometriosis and uterine leiomyomata: Findings from 
NHANES, 1999-2004. Environ Health Perspect 118: 825-832.

Wilson VS, Blystone CR, Hotchkiss AK, Rider CV, Gray LE (2008) Diverse mechanisms of antiandrogen action: Impact on male rat reproductive tract development. Int J Androl 31:178-187.

Xu Z, Liu J, Wu X, Huang B, Pan X (2017) Nonmonotonic responses to low doses of xenoestrogens: A review. Environ Res 155:199-207.

Zoeller Rt, Brown TR, Doan LL, Gore AC, Skakkebaek NE, Soto AM, Woodruff TJ, Saal FSV (2012) Endocrine-disrupting chemicals and public health protection: A statement of principles from the endocrine society. Endocrinology 153:4097-4110. 